Editor's Note: These short reviews of a recent paper in the Journal, written exclusively by graduate students or postdoctoral fellows, are intended to mimic the journal clubs that exist in your own departments or institutions. For more information on the format and purpose of the Journal Club, please see http://www.jneurosci.org/misc/ifa_features.shtml.

\title{
Differential Role of Slits in Dorsal versus Ventral Retinal Axon Guidance
}

\author{
Frédéric Causeret \\ Division of Neuroscience and Mental Health, Charing Cross Hospital, Imperial College, London W6 8RP, United Kingdom \\ Review of Thompson et al. (http://www.jneurosci.org/cgi/content/full/26/31/8082)
}

The establishment of accurate projections is essential to the precise functioning of neuronal structures. Furthermore, the acquisition of appropriate wiring patterns by neurons in sensory systems ensures the viability of the entire organism. Partly for this reason, the retina has, for over a century, grabbed the attention of well known scientists. Santiago Ramón y Cajal's (1911) pioneering work provided precise anatomical descriptions of the architecture of the retina, leading him to propose hypotheses about its function. In 1963, Roger Wolcott Sperry performed his eyeball rotation experiment, still taught to almost every student of neuroscience and developmental biology, which showed that growing axons are guided by chemical factors in their environment. Sperry's (1963) chemoaffinity hypothesis spurred a series of studies to investigate the role of axon guidance molecules in the development of the visual system, including the one that is the focus of a recent article in the Journal of Neuroscience by Thompson et al. (2006a). The authors addressed the role of Slit proteins in intraretinal axon guidance, the mechanisms by which axons growing from retinal ganglion cells (RGCs) form a layer at the internal surface of the retina, converging toward the optic

Received Aug. 7, 2006; revised Aug. 21, 2006; accepted Aug. 21, 2006.

F.C. was supported by a European Molecular Biology Organization Long Term Fellowship.

Correspondence should be addressed to Frédéric Causeret at the above address. E-mail: f.causeret@imperial.ac.uk.

DOI:10.1523/JNEUROSCI.3405-06.2006

Copyright $\odot$ 2006 Society for Neuroscience $\quad$ 0270-6474/06/269839-02\$15.00/0 disc. These projections then exit the retina to form the optic nerve. The pathfinding process of RGC axons is essential to the development of the visual system as defects in the internal organization of the retina affect the proper functioning of the eye. The authors focused on Slit1 and Slit2, two secreted proteins whose role as chemorepellents and growth inhibitors is well documented in different axonguidance systems. In particular, they took advantage of the availability of slit1- and slit2-deficient mice (Plump et al., 2002) to analyze the effects of the loss of these molecules on the establishment of retinal architecture.

Mutant mice were designed to express tau-green fluorescent protein (GFP) under the control of the endogenous slit1 or slit2 promoters, so that any cell that would normally express slit mRNA would express GFP in cell bodies and processes. Previous studies using in situ hybridization, a technique that allows identification of Slit expression in cell bodies but not fibers (the vast majority of mRNAs being restricted to the soma), demonstrated that both genes are expressed in the RGC layer of the retina (Erskine et al., 2000), but the identity of the expressing cells was not clear. The observation that GFP immunoreactivity is evident all along the RGC axon paths [Thompson et al. (2006a), their Fig. 1 (http://www.jneurosci.org/ cgi/content/full/26/31/8082/F1)] clearly establishes that RGCs are Slit1/2 expressing cells. After showing that RGCs express Slit proteins, Thompson et al. (2006a) performed GFP-staining on longitudinal and transversal sections of retinas obtained from slit1- and slit2-deficient animals and analyzed them by confocal microscopy. Interestingly, they identified two distinct defects in these sections (Fig. 1), each occurring specifically in either the ventral or dorsal parts of the retina.

The first abnormality [Thompson et al. (2006a), their Figs. 2B-I (http://www. jneurosci.org/cgi/content/full/26/31/ 8082/F2), 3 (http://www.jneurosci.org/ cgi/content/full/26/31/8082/F3)] consists of the occurrence of thick bundles of RGC axons mislocalized to the outer layers of the retina, opposite to the inner surface were RGC axons normally navigate. The defect is virtually absent from both wild-type and slit $1^{-/-}$retinas, but occurs with moderate (an average of five bundles per retina) and high frequency (over thirty bundles) in slit $2^{-1-}$ and slit1/2 doublemutant retinas, respectively [Thompson et al. (2006a), their Fig. 3C (http://www. jneurosci.org/cgi/content/full/26/31/ $8082 / F 3)]$. The results suggest that Slit1 and Slit 2 cooperate to maintain RGC axons in the inner surface of the retina. Strikingly, ectopic RGC axon bundles appear to form preferentially (greater than a 2:1 ratio) in the ventral rather than the dorsal part of the retina [Thompson et al. (2006a), their Fig. 3A,B,D (http://www. jneurosci.org/cgi/content/full/26/31/ $8082 / F 3)]$. This result points to a differential requirement for Slit1 and Slit2 expression in dorsally and ventrally originating RGC axons. The second abnormality ob- 
served in slit1 and slit2 mutant mice consists of a disorganization of the RGC axons within the RGC axons layer [Thompson et al. (2006a), their Figs. $2 J-Q$ (http://www.jneurosci.org/cgi/ content/full/26/31/8082/F2), 4 (http:// www.jneurosci.org/cgi/content/full/26/ $31 / 8082 / F 4)]$. Whereas fibers from slit $1^{-/-}$retinas appeared normal (in other words, parallel to one another), those from slit $2^{-/-}$and slit $1 / 2^{-/-}$organs were intermingled. Thus, lack of Slit2 is most likely solely responsible for this defect. In addition, only the dorsal retina was affected, particularly in its periphery, indicating another regional specificity for Slit protein function. It is noteworthy that axons exhibiting either defect appear to correctly exit the retina through the optic disc and grow along the optic nerve, as determined by microscopy after retrograde labeling from the chiasm [Thompson et al. (2006a), their Fig. 5 (http://www.jneurosci. org/cgi/content/full/26/31/8082/F5)], suggesting that Slit1 and Slit 2 act in coordination with other molecules to regulate retinal axon guidance. In addition, Thompson et al. (2006a) provide evidence [their Fig. 6 (http://www.jneurosci.org/cgi/content/full/ 26/31/8082/F6)] that loss of slit1 or slit2 does not affect the general morphology of the retina, demonstrating that the pathfinding defects they describe do not occur secondarily to modifications in the overall architecture of the retina.

The defects observed in the dorsal retina of mice lacking slit2 affected primarily peripheral fibers, localized near the lens. Thus, in the last series of experiments, the authors test the possibility that secretion of Slit proteins by nonretinal ocular tissues, in particular the lens, influences RGC axon development. Using an in vitro assay in which they cocultured explants of retina with lens tissue, Thompson et al. (2006a) [their Fig. 7 (http://www.jneurosci. org/cgi/content/full/26/31/8082/F7)] demonstrated that the lens exhibits a weak growth inhibiting activity on RGC axons originating from the ventral retina and a strong effect on dorsal axons. The inhibitory effect of the lens is likely to be mediated by Slit1 and Slit2, because loss of either molecule results in a significant reduction of the inhibitory effect.

Together, the results published by Thompson et al. (2006a) bring significant insights into the mechanisms of retinal development. First, they add Slits to the list of molecules implicated in these processes as their absence cause important retinal pathfinding defects. However, loss

\section{Dorsal}

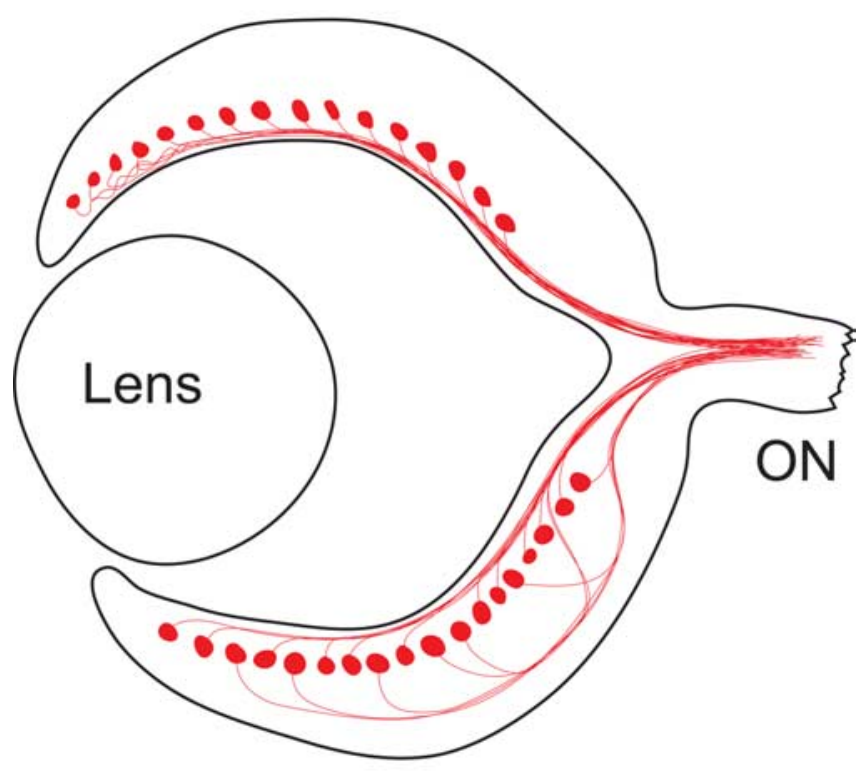

Ventral

Figure 1. Representation of the defects observed in retinas lacking slit. RGCs are represented in red; their axons form an internal superficial layer and exit the eye through the optic nerve $(\mathrm{ON})$. In the dorsal retina, absence of Slits results in the disorganization of the RGC axons in the peripheral regions, close to the lens. Ventrally, thick RGC axon bundles extend in outer layers of the retina instead of being restricted to the superficial layer. However, these ectopic axons successfully reach the optic nerve.

of both Slit1 and Slit 2 does not prevent RGC axons to exit the retina, indicating that these two molecules act alongside other factors in retinal axon guidance. More importantly, the study reveals a differential dependence on Slit protein expression by the dorsal and ventral RGCs populations. To date, this is the first example of a difference between dorsal and ventral RGC axon response to a diffusible factor. It does suggest that dorsal and ventral RGCs do not share the same signaling components (transmembrane receptors or intracellular signaling complexes). Alternatively, extracellular molecules specifically expressed in dorsal or ventral retina could interact with Slits, thus impairing or synergizing their effect on RGC axons. In another recent publication, the same group of authors describes defects caused by the loss of Slits in the tracts formed by RGC axons as they navigate in the diencephalon toward their target, the superior colliculus (Thompson et al., 2006b), indicating that Slits regulate multiple aspects of RGC axon pathfinding. Because Slits appear (1) to influence both intraretinal and extraretinal guidance and (2) to differentially affect RGC axons originating from ventral and dorsal retina, it is inter- esting to speculate that these molecules might be important for the establishment of the topography of the projections.

\section{References}

Erskine L, Williams SE, Brose K, Kidd T, Rachel RA, Goodman CS, Tessier-Lavigne M, Mason CA (2000) Retinal ganglion cell axon guidance in the mouse optic chiasm: expression and function of robos and slits. J Neurosci 20:4975-4982.

Plump AS, Erskine L, Sabatier C, Brose K, Epstein CJ, Goodman CS, Mason CA, Tessier-Lavigne M (2002) Slit1 and Slit2 cooperate to prevent premature midline crossing of retinal axons in the mouse visual system. Neuron 33:219-232.

Ramón y Cajal S (1911) Histologie du Système Nerveux de l'Homme et des Vertébrés. Paris: A. Maloine.

Sperry RW (1963) Chemoaffinity in the orderly growth of nerve fiber patterns and connections. Proc Natl Acad Sci USA 50:703-710.

Thompson H, Camand O, Barker D, Erskine L (2006a) Slit proteins regulate distinct aspects of retinal ganglion cell axon guidance within dorsal and ventral retina. J Neurosci 26:8082-8091.

Thompson H, Barker D, Camand O, Erskine L (2006b) Slits contribute to the guidance of retinal ganglion cell axons in the mammalian optic tract. Dev Biol 296:476-484. 